\title{
Variabilidade genética interespecífica em formigas cortadeiras do gênero Acromyrmex que ocorrem no Estado do Rio Grande do Sul
}

\author{
Inter-specific genetic variability of leaf cutting ants (Acromyrmex genus) from Rio Grande do Sul State
}

\author{
Douglas Daniel GrutzmacherI Alci Enimar Loeck ${ }^{\mathrm{I}}$ Antônio Costa Oliveira ${ }^{\mathrm{II}}$ Paulo Dejalma Zimmer \\ Gaspar Malone ${ }^{\mathrm{II}}$
}

RESUMO

São poucos os taxonomistas que atuam na identificação de formigas cortadeiras. Os métodos morfométricos utilizados nem sempre permitem uma identificação confiável, em função do acentuado polimorfismo dentro do mesmo formigueiro. O objetivo do trabalho foi testar a possibilidade do uso da ferramenta da biologia molecular para auxiliar na identificação das espécies de formigas cortadeiras do gênero Acromyrmex que ocorrem no Estado do Rio Grande do Sul. O estudo foi realizado com seis espécies de formigas do gênero Acromyrmex coletadas em quatro regiões do RS. Utilizaram-se as técnicas RAPD e AFLP, testando-se inicialmente 50 primers, dos quais apenas 13 foram selecionados por terem amplificado com sucesso fragmentos de todas as espécies estudadas. Embora os 13 primers selecionados tenham produzido fragmentos que permitem várias alternativas de seu uso para a identificação das espécies A. heyeri, A. ambiguus, A. crassispinus, A. striatus, A. laticeps e A. aspersus, a identificação das mesmas poderá ser realizada utilizando-se apenas os primers UBC 354, UBC 348 e UBC 356, que apresentaram fragmentos bem visíveis, que permitem uma identificação segura. Os resultados obtidos com o dendograma e as características morfológicas analisadas mostram que as espécies A. striatus e A. laticeps são menos relacionadas com as demais espécies estudadas, enquanto maior proximidade genética foi observada entre as espécies $\boldsymbol{A}$. ambiguus e A. crassispinus. Através deste trabalho, pode-se concluir que a identificação das espécies de Acromyrmex pode ser realizada de maneira segura pelas técnicas RAPD e AFLP.

Palavras-chave: Quenquéns, RAPD, AFLP, Primers.

\section{ABSTRACT}

At present, a few number of taxonomists work on identification of leaf cutting ants. Morphological-based methods do not always produce a reliable identification, due to the strong polymorphism observed even in the same colony. This fact leads to hypothesize that, besides those variations, others may also occur related to geographic distribution of the ants. Six Acromyrmex species were sampled at four locations in the State of Rio Grande do Sul and analyzed by RAPD and AFLP. Fifty UBC primers, originated from the University of British Columbia, were evaluated to select a set of primers that could be useful for species identification and genetic variability studies. Only 13 primers, which amplified fragments of all species, were selected. Although the selected primers produced fragments that allowed various ways for identification of $\boldsymbol{A}$. heyeri, A. ambiguus, A. crassispinus, A. striatus, A. laticeps and A. aspersus, only UBC 354, UBC348 and UBC356 primers allowed a reliable identification showing the most visible fragments. Results by dendogram and morphological-based identification, showed that A. striatus and A. laticeps are less related to the other species. However A. ambiguus e A. crassispinus are the most genetically related ants in the State of Rio Grande do Sul. The results indicate that a reliable identification of Acromyrmex can be carried out by RAPD and AFLP, yet allowing verification of genetic distance between species.

Key words: Quenquens, RAPD, AFLP, Primers.

\section{INTRODUÇÃO}

A identificação correta de um inseto é de fundamental importância para o desenvolvimento de trabalhos científicos, seja qual for o campo a ser estudado. A identificação de formigas cortadeiras pertencentes ao gênero Acromyrmex é mais complexa quando comparada às do gênero Atta, pela inexistência de soldados, utilizando-se para isso operárias de maior tamanho. Esse parâmetro é variável em função da idade

'Departamento de Fitossanidade, Faculdade de Agronomia "Eliseu Maciel”/Universidade Federal de Pelotas (FAEM/UFPel), Campus Universitário s/n, CP 354, Pelotas, RS, Brasil. E-mail: douglasdanielg@terra.com.br. Autor para correspondência.

"Departamento de Fitotecnia, FAEM/UFPel, Campus Universitário, Pelotas, RS, Brasil. 
do ninho, da época do ano, além da grande variabilidade fenotípica existente.

Cada espécie apresenta características próprias, como nidificação, comportamento, hábitos de corte de folhas e especificidade de coleta de material. $\mathrm{O}$ desconhecimento desses fatores tem muitas vezes levado ao insucesso de controle. Portanto, a correta identificação das formigas em questão é o primeiro passo a ser seguido.

Atualmente, a identificação de formigas cortadeiras é realizada, basicamente, observando-se suas características morfológicas externas. No entanto, é reduzido o número de taxonomistas que atuam na identificação de formigas cortadeiras. Os métodos morfométricos utilizados nem sempre permitem uma identificação confiável, em função do acentuado polimorfismo dentro da mesma colônia. Esses pressupostos levam a pensar que além dessas variações, dentro da mesma espécie, devam existir outras relacionadas com a região geográfica.

As formigas cortadeiras estão disseminadas em todo o território nacional e atacam praticamente todas as plantas cultivadas, causando elevados prejuízos à agricultura convencional, ao reflorestamento e às pastagens (LOECK \& GRUTZMACHER, 2001). Os resultados de pesquisas em andamento mostram que o comportamento das diferentes espécies de formigas cortadeiras, em relação às medidas de controle químico, estão a exigir maiores e mais profundos estudos, especialmente sobre a identificação correta das espécies, sua distribuição geográfica e as melhores épocas para a adoção de medidas de controle (LINK, 1999).

No Rio Grande do Sul (RS), as formigas cortadeiras predominantes pertencem ao gênero Atta (saúvas) e Acromyrmex (quenquéns). Ambas cortam folhas e as transportam para o interior do formigueiro onde, em câmaras especiais, são utilizadas como meio de cultura de um fungo, do qual se alimentam. Segundo LOECK \& GRUTZMACHER (2001), no Estado do RS, são encontradas dez espécies de formigas cortadeiras pertencentes ao gênero Acromyrmex, enquanto GUSMÃO \& LOECK (1999), estudando apenas a Região Sul do Estado do RS, encontraram sete espécies.

Cada espécie de formiga apresenta hábito de corte e nidificação diferente, tem hábitos próprios e vive em locais determinados (GONÇALVES, 1945).

Os métodos morfométricos tradicionalmente utilizados para identificação de insetos apresentam muitas limitações em alguns grupos, tanto pela ambigüidade inerente ao seu uso como pela dificuldade de serem aplicados em alguns estádios de desenvolvimento do inseto (CENIS, 1994). Isso tem motivado a aplicação de técnicas baseadas no estudo de diferenças genéticas, de utilização mais difícil, porém mais estáveis e objetivas.

Marcadores isoenzimáticos podem auxiliar a identificação de espécies de formigas do gênero Acromyrmex (AUGUSTIN et al., 1999). Além dos Marcadores isoenzimáticos, os Marcadores de DNA têm sido utilizados para estudos de diversidade genética em várias espécies animais e vegetais (WALDSCHMIDT et al., 1997), sendo que seu uso tem revolucionado e resolvido importantes problemas em espécies pouco estudadas.

As dificuldades dos ensaios baseados no fenótipo podem ser eliminadas através da identificação direta do genótipo por meio de ensaios diagnósticos usando-se marcadores genéticos baseados no DNA em vários sistemas genéticos (BECKMAN \& SOLER, 1983).

Marcadores de RAPD podem ser muito úteis para estudos genéticos de abelhas (HUNT \& PAGE Jr., 1992). De acordo com LANDRY et al. (1993), pela taxonomia tradicional não é possível diferenciar biótipos dentro de espécies de microhimenópteros. Por isso, vem-se utilizando a técnica RAPD para detectar os desvios genéticos ocorridos durante diversas gerações.

Com o uso de técnicas para detectar polimorfismos das seqüências de DNA, determinaramse as relações genéticas entre indivíduos. Para a determinação destas relações, têm sido usados RFLPs (Restriction Fragment Length Polymorphisms) (BOTSTEIN et al., 1980), que são marcadores baseados na capacidade de endonucleases de restrição reconhecerem posições-alvo nas seqüências específicas de bases de DNA. Posteriormente, foi desenvolvida a técnica PCR, a qual detecta polimorfismos pela ampliação seletiva de fragmentos específicos de DNA e pela separação dos mesmos por eletroforese em gel (INNIS et al., 1990). Através desta técnica, os ensaios genéticos podem se tornar mais rápidos e menos trabalhosos do que a técnica de RFLPs.

Depois da técnica de RFLPs, foi desenvolvido um novo ensaio genético chamado RAPD, o qual detecta polimorfismos numa seqüência de nucleotídeos através da ampliação do DNA usandose apenas um primer de seqüência arbitrária de nucleotídeos (normalmente 10 a 12 bases) (WILLIAMS et al., 1990). Neste caso, um único primer liga-se ao DNA genômico em dois sítios diferentes nos cordões do DNA-template. Se estes sítios estão a uma certa distância um do outro, há formação de produtos de DNA através da ampliação termocíclica. A presença de cada produto identifica, completa ou parcialmente, uma seqüência de nucleotídeos homólogos entre o DNA genômico e o primer em cada extremidade do produto 
ampliado. Na média, cada primer dirigirá a ampliação de vários sítios no genoma, tornando o ensaio um eficiente modo de seleção para polimorfismos de seqüência de nucleotídeos entre indivíduos. A maior vantagem desse método é a de que não há necessidade de informação de seqüência do DNA genômico. O ensaio é relativamente simples e fácil de ser realizado, não utilizando material radioativo, necessitando uma quantidade mínima de DNA (nanogramas).

As aplicações do RAPD são similares àquelas do RFLP, ou seja, os polimorfismos podem ser usados como marcadores genéticos a fim de determinar relações genéticas, tais como identificação varietal e determinação de parentesco, bem como identificar e mapear sítios que afetam características quantitativas (WELSH et al., 1991).

A técnica de AFLP (Amplified Fragment Length Polymorphisms) está entre as mais recentes aplicações do método de PCR . Este método envolve quatro etapas incluindo: digestão do DNA com enzimas de restrição, uma de corte raro ( $E c o$ RI) e outra de corte freqüente (Mse I); ligação de adaptadores específicos; amplificação seletiva de fragmentos com primers específicos e separação de fragmentos amplificados em gel de poliacrilamida.

Especificamente em relação ao gênero Acromyrmex, até o presente momento não tem sido utilizada essa moderna ferramenta da biologia molecular para auxiliar na identificação das espécies de formigas cortadeiras que ocorrem no Estado do RS. O objetivo do trabalho foi testar a possibilidade do uso da ferramenta da biologia molecular para auxiliar na identificação das espécies de formigas cortadeiras do gênero Acromyrmex que ocorrem no RS.

\section{MATERIAL E MÉTODOS}

Para verificar a variabilidade interespecífica das espécies de Acromyrmex nas diferentes regiões e a possibilidade da amplificação do DNA extraído, através da técnica de RAPD, foram testados inicialmente 50 primers (UBC 441 a UBC 490, obtidos da University of British Columbia, Canada).

$\mathrm{O}$ processo de extração foi realizado em tubos tipo eppendorf de $1,5 \mathrm{~mL}$, sendo que, para cada extração, foram utilizadas cinco formigas inteiras. As formigas estocadas no álcool $75 \%$ permaneceram por cinco minutos sobre papel absorvente, como forma de eliminar o álcool previamente à extração.

O protocolo utilizado foi de OLERUP \& ZETTERQUIST (1994), constando do seguinte: as amostras foram maceradas em nitrogênio líquido e ressuspendidas em $500 \mu \mathrm{L}$ de tampão de extração (Tris HCl 10mM pH 8,0; NaCl 100mM; EDTA 10 mM pH 8,0; SDS $0,5 \%)$ adicionado de proteinase $\mathrm{K}\left(20 \mu \mathrm{g} \mathrm{mL} \mathrm{m}^{-1}\right)$.
Posteriormente, as amostras foram incubadas por duas horas a $37^{\circ} \mathrm{C}$ e centrifugadas por seis minutos a $14.000 \mathrm{~g}$. Ao sobrenadante, foram adicionados $260 \mu \mathrm{L}$ de TE e $240 \mu \mathrm{l}$ de $\mathrm{NaCl} 5 \mathrm{M}$, sendo centrifugado por 15 minutos a $14.000 \mathrm{~g}$. O sobrenadante foi transferido para novo tubo $(500 \mu \mathrm{l})$, ao qual foi adicionado o correspondente a duas vezes o seu volume em etanol, sendo então homogeneizado e, em seguida, centrifugado por 15 minutos a $14.000 \mathrm{~g}$. O precipitado foi lavado com $200 \mu \mathrm{L}$ de etanol 70\% gelado, seguido de nova centrifugação por cinco minutos a $14.000 \mathrm{~g}$ e ressuspensão do precipitado em $50 \mu \mathrm{L}$ de TE $\mathrm{pH} 8,0$.

Após as extrações, o DNA genômico obtido foi submetido à eletroforese em gel de agarose $1 \%$, à voltagem de 100 volts e tampão TBE (Tris base, ácido bórico e EDTA). ODNA foi colorido com $2 \mu \mathrm{L}$ de brometo de etídeo (1\%) e fotografado em transluminador ultravioleta (SAMBROOK \& FRITSCH 1989).

Na preparação das amostras para PCR, foram utilizados para cada eppendorff um total de $20 \mu \mathrm{g}$,

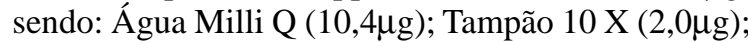

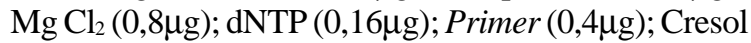
$\operatorname{red}\left(5,0 \mathrm{U} \mu \mathrm{L}^{-1}\right)$; Taq polimerase $(0,25 \mu \mathrm{g})$ e DNA $(1,00 \mu \mathrm{g})$.

As temperaturas utilizadas no termociclador na reação foram de $94^{\circ} \mathrm{C}$ por cinco minutos, seguindose de 40 ciclos de $94^{\circ} \mathrm{C}$ por 30 segundos, $35^{\circ} \mathrm{C}$ por um minuto e $72^{\circ} \mathrm{C}$ por um minuto. A extensão final foi de $72^{\circ} \mathrm{C}$ por sete minutos.

Como marcador molecular, utilizou-se o marcador Lambda Hind III $\left(0,1 \mu \mathrm{g} \mu \mathrm{L}^{-1}\right)$ e a concentração do DNA extraído foi obtido por comparação com as bandas deste marcador. As preparações das soluções foram obtidas a partir de soluções estoques, utilizandose para isso a seguinte fórmula: $\mathrm{M}_{1} \mathrm{x} \mathrm{V}_{1}=\mathrm{M}_{2} \mathrm{x} \mathrm{V}_{2}$.

Para a análise da variabilidade genética inter específica em formigas cortadeiras do gênero Acromyrmex, foram coletadas formigas vivas trazidas juntamente com uma porção do seu fungo em caixas de gerbox, para garantir a sobrevivência destas durante o transporte. A coleta foi realizada no mês de agosto de 2001 em quatro regiões distintas do Estado do Rio Grande do Sul: Região Sul (A. heyeri, A. ambiguus, $\boldsymbol{A}$. crassispinus e A. striatus), Região Metropolitana (A. heyeri, $A$. aspersus e A. laticeps), Região Noroeste (A. heyeri, $A$. ambiguus, A. laticeps e A. crassispinus) e Região da Depressão Central (A. heyeri, A. laticeps, A. ambiguus e A. crassispinus).

Inicialmente, foram testados 50 primers (UBC 441 a UBC 490) para que alguns destes pudessem ser selecionados para auxiliar na identificação e no estudo de variabilidade genética das formigas. A técnica AFLP também foi utilizada para o estudo da análise da variabilidade genética das formigas cortadeiras do gênero Acromyrmex que ocorrem no Estado do RS.

Ciência Rural, v.37, n.4, jul-ago, 2007. 
A análise estatística foi realizada a partir de uma matriz construída com dados binários da leitura dos géis ( 0 , ausência da banda, e 1 , presença da banda). Somente fragmentos (bandas) claramente visíveis e reproduzíveis em dois ou mais géis foram considerados para as análises. Os dados foram calculados usandose o programa SAS (Statistical Analysis System), conforme empregado por OLIVEIRA et al. (1996).

\section{RESULTADOS E DISCUSSÃO}

Dos 50 primers utilizados neste trabalho, apenas 13 foram selecionados por terem amplificado com sucesso fragmentos de todas as espécies estudadas. Embora, os 13 primers selecionados tenham produzido fragmentos que permitem várias alternativas de uso para a identificação das espécies $\boldsymbol{A}$. heyeri, $\boldsymbol{A}$. ambiguus, $A$. crassispinus, $A$. striatus, $A$. laticeps e A. aspersus, a identificação das mesmas poderá ser realizada utilizando-se apenas os primers UBC 354, UBC 348 e UBC 356, que apresentaram fragmentos bem visíveis, que permitem uma identificação segura, conforme mostrado na figura 1 .

A distância genética entre as espécies de Acromyrmex é apresentada como dendograma na figura 2A, construído a partir de dados de RAPD. Das 87

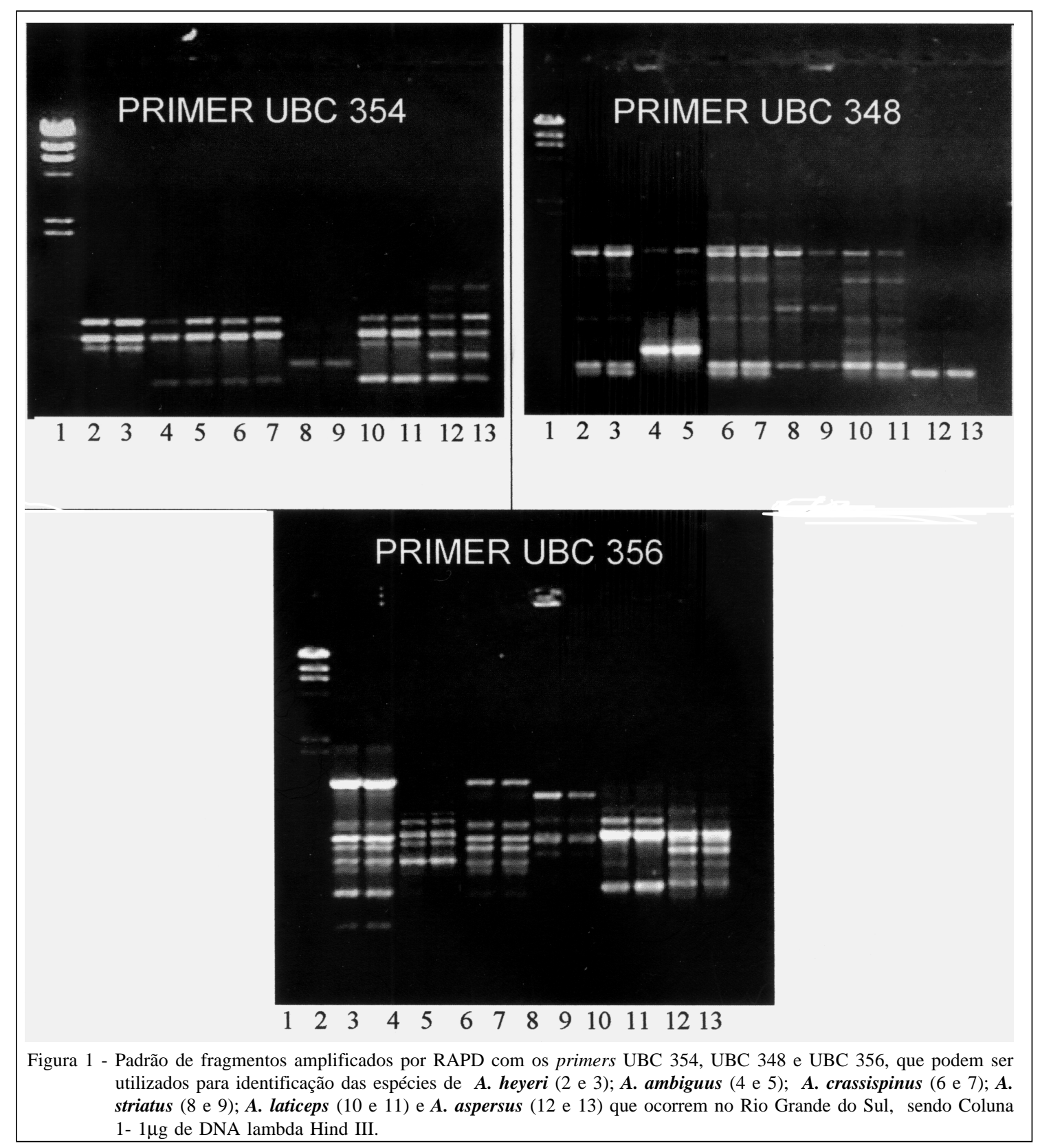

Ciência Rural, v.37, n.4, jul-ago, 2007. 


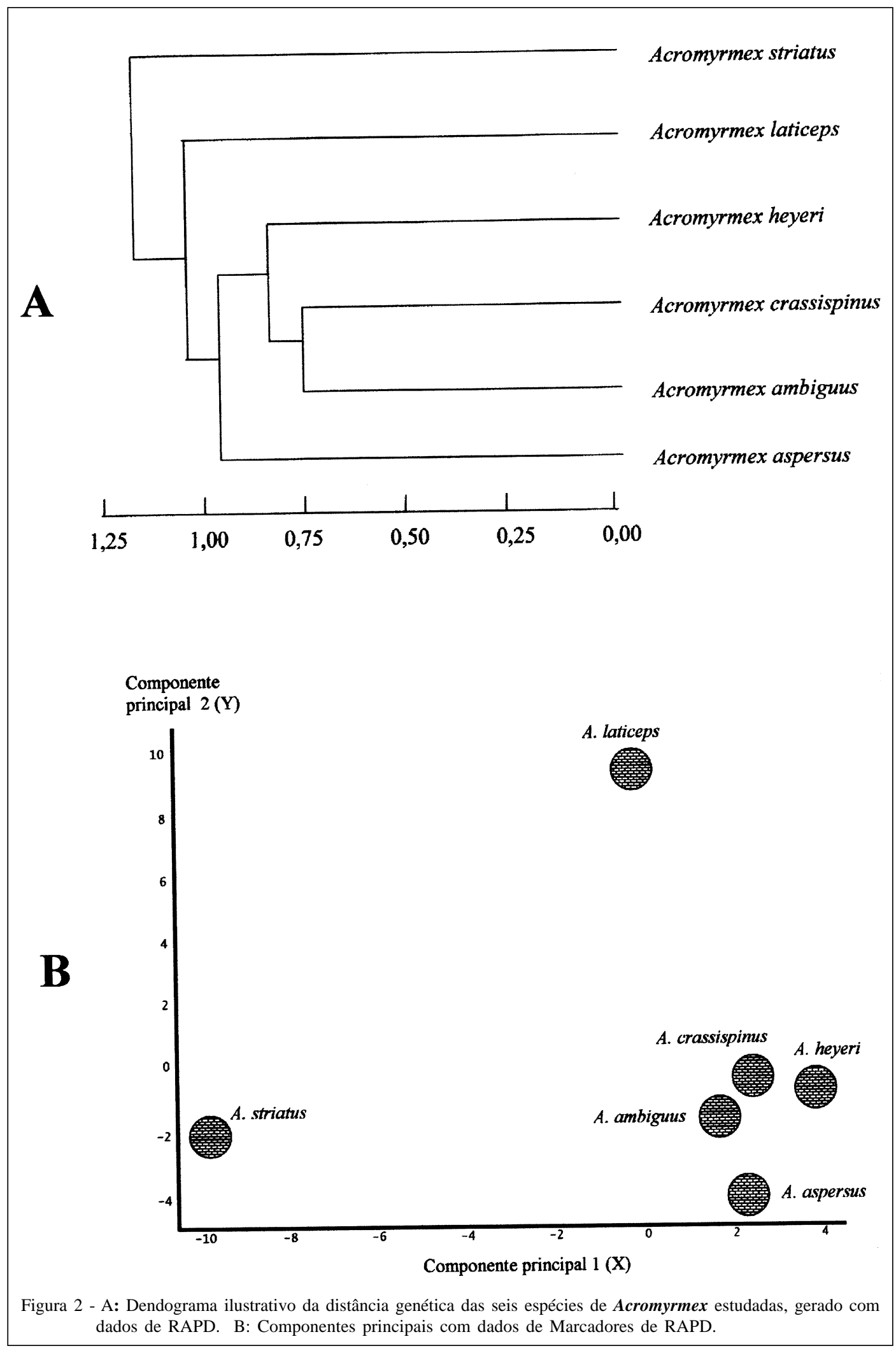

observações utilizadas na construção do dendograma, apenas cinco explicam $100 \%$ da diversidade genética encontrada, sendo que a primeira explica 29,3\% da diferença, a segunda $25,2 \%$, a terceira $22,0 \%$, a quarta

Ciência Rural, v.37, n.4, jul-ago, 2007. 
$14,0 \%$ e a quinta apenas $9,5 \%$. O dendograma foi construído a partir das 87 bandas geradas e mostra que a distância genética variou de 0,75 entre as espécies A. crassispinus e A. ambiguus até 1,10 na espécie $\boldsymbol{A}$. striatus, quando comparada com as demais espécies. Isto demonstra a proximidade existente entre $\boldsymbol{A}$. ambiguus e A. crassispinus e a distância genética destas com relação a $\boldsymbol{A}$. striatus, que é uma das espécies de fácil identificação. BORBA (2006), estudando o polimorfismo dos fungos de espécies de Acromyrmex, verificou que o fungo das espécies $\boldsymbol{A}$. crassispinus e A. ambiguus foram os mais similares. Estes dois trabalhos mostram a proximidade genética existente entre essas duas espécies de formigas.

A estriação longitudinal da cabeça de $\boldsymbol{A}$. striatus, o tipo de projeção do pecíolo e o gáster liso, sem tubérculos, são caracteres que não ocorrem em outras espécies, tanto é que MAYHÉ NUNES (1991) citou que o fato de ter o gáster desprovido de tubérculos e a ausência dos espinhos supra-oculares (caráter subgenérico) aproximam A. striatus do gênero Atta. Estes resultados mostram a associação de características morfológicas com o dendograma.

A figura 2B mostra a análise de componentes principais, reforçando os resultados obtidos com o dendograma e com características morfológicas (tamanho e formato da cabeça, tamanho dos espinhos, reticulação do tegumento, etc.) usadas para sua identificação, pois mostra que as espécies $\boldsymbol{A}$. striatus e A. laticeps estão menos relacionadas com as demais espécies estudadas, apresentando-se em posições mais distantes no gráfico.

A. laticeps apresenta algumas características morfológicas (tamanho e formato da cabeça) diferentes das demais espécies de Acromyrmex e, ao mesmo tempo, semelhantes às do gênero Atta, fatos estes que podem relacionar a maior proximidade desta espécie ao gênero Atta (LOECK \& GRUTZMACHER, 2001).

Além dos resultados observados no dendograma da figura 2A, observa-se na figura $2 \mathrm{~B}$ a proximidade genética entre as espécies $A$. ambiguus e A. crassispinus. Morfologicamente, estas duas espécies também apresentam várias características em comum.

Com relação à técnica AFLP, os dados obtidos foram muito semelhante aos dados de RAPD, nos quais também se observou que as amostras de $\boldsymbol{A}$. crassispinus e $\boldsymbol{A}$. ambiguus são muito próximas geneticamente. Com relação às amostras de $\boldsymbol{A}$. striatus e A. laticeps, novamente estes dados concordam com os dados obtidos com RAPD, sendo estas duas espécies as mais distantes geneticamente das demais espécies estudadas (A. heyeri, A. aspersus, $\boldsymbol{A}$. ambiguus e A. crassispinus).

\section{CONCLUSÕES}

A identificação das espécies de Acromyrmex pode ser realizada associando-se os dados morfológicos com as técnicas RAPD e AFLP através da amplificação do DNA extraído. As técnicas RAPD e AFLP permitem verificar a distância genética entre as espécies de formigas cortadeiras.

\section{REFERÊNCIAS}

AUGUSTIN, E. et al. Identificação de formigas cortadeiras do gênero Acromyrmex (Hymenopetra: Formicidae) através de isoenzimas. Revista Brasileira de Agrociência, v.5, n.3, p.216-219, 1999.

BECKMANN, J.S.; SOLER, M. Restriction fragment lenght polymorphisms in genetic improvement: methodologies, mapping and costs. Theor Appl Genet, v.67, p.35-43, 1983.

BORBA, R. da S. Aspectos morfológicos, nutricionais e genéticos do fungo simbionte de formigas cortadeiras. 2006. 93f. Tese (Doutorado em Fitossanidade) - Curso de Pósgraduação em Fitossanidade, Universidade Federal de Pelotas.

BOTSTEIN, D. et al. Construction of a genetic map in man using restriction fragment lenght polymorphisms. American Journal Human Genetics, v.32, p.314-31, 1980.

CENIS, J.L. Aplication de la técnica RAPD-PCR (ADN polimorfico amplificado al azar) a la identificacion de insectos. Investigacion agraria. Producion y Proteccion Vegetales, v.9, n.2, p.289-297, 1994

GONÇALVES, C.R. Saúvas do Sul e Centro do Brasil. In: Boletim Fitossanitário. Rio de Janeiro: Ministério da Agricultura do Brasil, 1945. p.183-218. (Boletim Técnico, 2).

GUSMÃO, L.G. de; LOECK, A.E. Distribuição geográfica de formigas cortadeiras do gênero Acromyrmex (Hymenoptera: Formicidae) na Zona Sul do Estado do Rio Grande do Sul, Brasil. Revista Brasileira de Agrociência, v.5, n.1, p.64-67, 1999.

HUNT,G.J; PAGE Jr, R.E. Patterns of inheritance with RAPD molecular markers reveal novel types of polymorphism in the honey bee. Theoretical and Applied Genetics, v.85, p.1520, 1992.

INNIS, M.A. et al. PCR protocols. San Diego: Academic, 1990. 482p.

LANDRY, B.S. et al. Random amplified polymorphic DNA markers for DNA fingerprinting and genetic variability assessment of minute parasitic wasps species (Hymenoptera: Mymaridae and Trichogrammatidae) used in biological control programs of phytophagous insects. Genome, v.36, p.580587, 1993.

LINK, D. Formigas: pequenas e chatas. Cultivar, Pelotas, v.09, p.31-32, 1999.

LOECK, A.E.; GRUTZMACHER, D.D. Ocorrência de formigas cortadeiras nas principais regiões 
agropecuárias do Estado do Rio Grande do Sul. Pelotas: UFPel, 2001. 147p.

MAYHÉ-NUNES, A.J.

Estudo de Acromyrmex (Hymenoptera, Formicidae) com ocorrência constatada no Brasil: subsídios para uma análise filogenética. 1991. 122f. Dissertação (Doutorado em Entomologia) - Curso de Pós-graduação em Entomologia, Universidade Federal de Viçosa.

OLERUP, O.; ZETTERQUIST, H. HLA-DR typing by PCR amplification witch sequence Specific primer (PCR-SSP) in 2 hours: An alternative to serological DR typing in clinical practice including donor-repient matching in cadaveric transplantation. Tissue Antigens, v.39, p.225-235, 1994.

OLIVEIRA, A.C. et al. Regional and racial specificities in sorghum germplasm assessed with DNA markers. Genome, v.39, p.579-587, 1996.
SAMBROOK, J.; FRITSCH, E.F. Molecular cloning: a laboratory manual. 2.ed. New York: Cold Spring Laboratory, 1989. p16-23.

WALDSCHIMIDT, A.M. et al. Extraction of genomic DNA from Melipona quadrifasciata (Hymenoptera: Apidae, Meliponae). Brazilian Journal of Genetics, v.20, n.3, p.421423, 1997.

WELSH, J. et al. Polimorphisms generated by arbitrary primed PCR in the mouse: Application to strain identification and genetic mapping. Nucleic Acids Res, v.19, p.303-306, 1991.

WILLIAMS, J.G.K. et al. DNA polymorphisms amplified by arbitrary primers are useful as genetic markers. Nucleic Acids Res, v.18, p.6531-6535, 1990. 